Finisterra, XXXVI, 72, 2001, pp. 55-66

\title{
A PAISAGEM REVISITADA
}

Álvaro Domingues ${ }^{1}$

Resumo - Na Geografia Clássica, a paisagem constituía um conceito central, coerentemente construído, objecto de uma forte consensualidade e referência inultrapassável da própria Geografia. A turbulência própria da epistemologia recente da Geografia, quase apagou esse legado, chegando até a estigmatizá-lo como travão de uma urgente renovação disciplinar neo-positivista.

Usando uma metáfora conhecida, aquilo que despejámos pela porta, entrou-nos agora por todas as janelas e nem sempre da melhor maneira: para uns um simples retorno ao passado, mas também uma ameaça exterior ao património mais valioso da Geografia; para outros, a impressão de que alguém nos ultrapassou por entre o ziguezaguear permanente que tem caracterizado a fragmentação do campo geográfico.

Ao contrário, defendemos que esta súbita procura social da Paisagem, nos abre um novo campo de reflexão e de investigação, hoje, como outrora, enriquecido pela pluralidade de sentidos que o conceito contém.

Abstract - BACK TO LANDSCAPE - Natural landscape in classical geography was a coherently constructed and universally acknowledged central concept and unquestionably part of geography itself. Hot debate that arose from recent epistemology in geography nearly brought this heritage to an end and even accused it of acting as a brake on the urgent need for scientific renewal.

As an old saying goes, what we throw out through the door comes back through every window and not always in the best manner: for some, it is a simple return to the past, although it also poses an external threat to geography's highest achievement; for others, the impression is that someone has overtaken us in this constant toing and froing that has split the field of geography.

However, we maintain that this sudden interest in landscape opens up to us new domains for reflection and investigation, which is, as it was in the past, enriched by the plurality of meanings it embraces.

After examining other disciplines (such as aesthetics, anthropology, landscape ecology, and architecture landscape), we return to geographical landscape with the aim of showing a fresh way of looking at things and the new possibilities this concept opens.

1 Geógrafo, Faculdade de Arquitectura da Universidade do Porto. E-mail: alvarodomingues@netc.pt 
[1] É quase sempre com uma atitude nostálgica que hoje se aborda o conceito de "paisagem» na Geografia. A paisagem, numa época em que a geografia se afirmava uma disciplina de charneira entre as ciências físicas e humanas, era uma espécie de síntese e epifenómeno resultante de uma relação de tempos longos entre as condições naturais (um conjunto de determinantes biofísicas) e a acção do homem organizado em sociedades portadoras de uma historicidade, de uma cultura, de uma evolução tecnológica.

Mais do que uma morfologia, ou de uma tipificação de morfologias, as paisagens geográficas continham uma espessura antropológica, uma memória reveladora de diversas sedimentações ou marcas deixadas por sucessivas transformações. As paisagens eram património cultural, elemento imprescindível da identidade de um povo ou até de um modelo de coesão do Estado-Nação. De resto, ideologicamente, as regióes - áreas de extensão de unidades e padrões de paisagem -, legitimavam as teses orgânicas do equilíbrio da nação na sua diversidade e relação entre ambientes («meios geográficos») e "modos de vida», e o quadro estável do mosaico das paisagens-tipo de cada região.

Quase sempre enquadrada por uma sociedade rural e tradicional, a Geografia das Paisagens devolvia-nos a segurança de um saber estável, coerente, reconhecível em equilíbrios engenhosos, duradouros e saberes ancestrais. O estudo da Paisagem era quase um exercício de sedução: desmontar para perceber, relacionar, encontrar as marcas do tempo, as vicissitudes da história, as estações, os campos, as formas de povoamento, as construções, os materiais. Mais do que um simples conceito, o estudo da paisagem (e, por associação, a região geográfica) identificava-se com o próprio objecto de estudo da Geografia e o elemento distintivo de um posicionamento disciplinar claro entre as ciências naturais e as ciências humanas.

Fora do campo científico, o sucesso desta «Geografia das Paisagens» (um recente quase-pleonasmo) não podia ter sido mais eficaz, particularmente em Portugal onde a ideologia dominante até à Revolução de Abril de 74 se baseava num país rural, atávico, tradicionalista, cioso da sua memória histórica e dos particularismos do seu território diverso «entre o Mediterrâneo e o Atlântico» (a expressão cara a Orlando Ribeiro), matizado pela orografia, pela interioridade ou pela proximidade ao mar, pela diversidade do seu mosaico paisagístico e de todo o folclore associado a uma imagem idílica e romântica das suas gentes e costumes (no âmbito da construção do conceito de paisagem em Portugal, está por estudar a importância da obra de O. Ribeiro na ideologia paisagístico-ruralista do Estado Novo). A paisagem fixou-se, assim, na sua dupla condição de realidade física e de construção ideológica, socialmente inculcada e difundida como um dos factores centrais da identidade nacional (CORBIN, 2001: 151-182).

[2] No passado recente, esta estabilidade desfez-se rapidamente. Portugal, o último país rural da Europa, conheceu transformações profundas e radicais: uma sociedade que se urbaniza, vastos territórios em tensão (des)po- 
voados, ainda vividos pelos últimos guardiões de culturas rurais tradicionais, envelhecidos; regiões esvaziadas, ruínas, abandono, mas também novas construções, novos modos de vida, auto-estradas, casas novas, novos sinais dissonantes na harmonia das paisagens de outrora. Quase ao mesmo tempo, em pouco menos de trinta anos e num ambiente de forte turbulência disciplinar, assistimos, sucessivamente, a uma recentragem múltipla e instável da Geografia em dois conceitos-chave: o espaço e o território. A síntese naturalista e historicista que alicerçava a Paisagem quase se extinguiu, não tanto por um processo de falsificação "popperiano" (aliás, a reflexão epistemológica nunca foi elemento central na Geografia Clássica de inspiração Vidaliana e de autores alemães) mas, sobretudo, por redução ou por negação, para dar lugar aos novos paradigmas emergentes.

O Espaço Geográfico, conceito de raiz neo-positivista, construiu-se com base numa ciência teorética que pretendia exorcizar a Paisagem como um verdadeiro obstáculo à construção de uma ciência que negava o excepcionalismo do discurso "paisagístico» e o seu carácter descritivo e, em última análise, subjectivo. Os novos ventos corriam de feição para uma Geografia de base económica, apoiada numa construção modélica e quantitativa. A velha síntese geográfica desaparece, dando um lugar a uma divisão mais profunda entre Geografia Física e Humana, sobretudo em termos de objecto e menos no método de estudo.

Quase ao mesmo tempo, o conceito de Território (algo que remete de imediato para a ideia de um espaço geográfico socialmente apropriado, regulado e construído) veio provocar uma nova inflexão no percurso da Geografia. $O$ radicalismo inicial, de raiz marxista e politicamente empenhado, traz a Geografia para o campo sociológico, centrando a explicação do Território como produto/construção social, lugar de confronto, de tensões, de conflitos de uso e de apropriação e transformação.

No meio desta turbulência a Paisagem resiste disciplinarmente (BESSE, 2000), se bem que de um modo residualista, seja por um efeito geracional (a tenacidade de uma certa geração de geógrafos na defesa e nas tentativas de renovação de um dos conceitos fundadores da Geografia), seja pela sua forte impregnação no discurso não disciplinar, seja por pequenas adaptações por parte de uma Geografia Histórica e Culturalista. Entretanto, a emergência das teses ambientalistas (o eco-desenvolvimento, a formação de uma consciência ambiental, as teses do desenvolvimento dito sustentável, os paisagistas do ordenamento do território, etc.) dentro e fora do campo estritamente geográfico, veio a dar um renovado fôlego e actualização do conceito de Paisagem, se bem que em contextos científicos muito diversificados mas com alguma resistência inicial da Geografia, entretanto pulverizada em especializações, autores e compromissos inter-disciplinares vários.

[3] Este ressurgimento da Paisagem é, por razões várias, bastante mais complexo do que um simples retorno à «velha» Geografia: 
- a paisagem deixa de ser (se é que alguma vez o foi) uma espécie de património hegemónico da Geografia;

- as novas ciências do ambiente ou a incorporação das variáveis ambientais noutros campos disciplinares (desde a biologia, ao planeamento, ao urbanismo, ao paisagismo, à economia), constituem, ao mesmo tempo, uma fonte de enriquecimento da Geografia, mas também uma ameaça à própria referenciação e caracterização do seu objecto de estudo;

- a importância nunca perdida da abordagem da paisagem no campo da Estética, da História da Arte, da Antropologia ou da Etnologia, da Literatura (Roger, 1997; BERQue, 1995; LENCLUd, 1995), lançam um olhar novo sobre a questão e contribuem para a afirmação e a divulgação crescente de um olhar esteticista sobre a paisagem, a sua "artialisation», no sentido de Roger (1997: 112);

- a emergência da importância dos valores patrimoniais (juntamente com os ambientais), conferem à paisagem uma grande visibilidade social (originando até instrumentos específicos de protecção e de regulação no âmbito do ordenamento do território e do urbanismo), o que não só aumenta a diversidade dos estudos e dos investigadores da paisagem, como contribui para o reforço dos valores da «autenticidade» cultural das «paisagens patrimoniais» (VoISEnat; NotTEGHem, 1995).

«...c'est de la conjonction de ces deux facteurs - détérioration in situ, déréliction in visu - que procède la crise actuelle du paysage. Mais est-elle aussi grave? Je crois qu'elle trahit surtout la sclérose de notre regard, qui veut du vieux, et le recours nostalgique à des modèles bucoliques, plus ou moins périmés, des paysâges, des paysâgés (...) À nous forger les schémas de vision, qui nous les rendront esthétiques» (RoGER, 1997: 113)

- a diversificação da polisemia do conceito e a sua múltipla apropriação, quer por parte das novas disciplinas emergentes no campo ambiental (p.e., a Ecologia da Paisagem), quer por inúmeras construções de base ideológica no campo, por exemplo, da promoção turística. Veja-se, a este propósito, as razões e as construções retóricas do processo recente de «mise en paysage» em França (Voisenat; Notteghem, 1995).

[4] Perpassa por toda esta diversidade uma situação de tensão e de indefinição que os autores citados atrás equacionam da seguinte forma: à questão «o que é a paisagem?» substitui-se uma outra «quem fala (ou não) da paisagem, como e porquê?». A estes questionamento, Augustin Berque responde com algumas possíveis frentes de problematização (BERQUE, 1995):

- as representações linguísticas ou semióticas;

- as representações literárias, orais ou escritas, cantando ou descrevendo as belezas da paisagem; 
- as representações pictóricas;

- as interpretações paisagísticas, traduzindo uma visão estética da natureza.

Comparando com a etimologia francesa "pays/paysans/paysages», a portuguesa parece não andar muito longe (a raiz etimológica de paisagem é de origem francesa, traduzindo, embora um duplo significado: paysans pode referir-se aos habitantes de um determinado pays, como, mais literalmente, aos camponeses).

Esta raiz etimológica é concordante com o conteúdo ruralista do conceito tradicional de Paisagem em Geografia. A suposta estabilidade das paisagens regionais (identificadoras das Regiões Geográficas) corresponde, de facto, a uma situação em que os modos de vida rurais tradicionais e, por isso, as actividades agrícolas, detinham uma importância central nos processos longos da «construção das paisagens». A perda dessa estabilidade, concomitante com o processo de êxodo rural e agrícola, com a modernização ou a decadência das actividades agro-silvo-pastoris, etc., constitui o elemento mais claro da «crise» da paisagem. Esta situação de tensão, enunciada muitas vezes como um estado de "degradação ou de descaracterização das paisagens», assume de facto contornos e resultados diversos:

- a descaracterização pode ser, simplesmente um processo de desconstrução (de destruição, no limite) das paisagens "funcionais» tradicionais, explicado pelas mudanças sociais nos modos de apropriação, uso e de transformação dos territórios rurais. Dada a maior rigidez de transformação das paisagens in situ (RoGER, 1997), face à velocidade das mudanças sociais, pode-se originar uma situação paradoxal em que aquilo que se vê ou que nos é descrito, caracterizado ou inculcado (a paisagem in visu) já não é explicado ou concordante com os estereótipos tradicionais. Verifica-se, assim, uma espécie de dinâmica em diferido, onde a «resistência» de determinados padrões de paisagem lida, pelo menos, ao nível da permanência de determinados elementos visuais estruturantes (so-calcos, soutos ou bouças de carvalhos, por exemplo), produz um sentimento de perda e de ameaça. A «disfunção» é um momento mais ou menos longo que medeia a mudança das condiçóes sociais produtoras, a prazo, de novas paisagens (e a sua nova estabilização mais ou menos efémera), e a permanência frágil (porque não garantida socialmente), in visu, da coerência funcional e estética da outra paisagem. Ocorre aqui a velha metáfora da paisagem como palimpsesto, o texto que desaparece deixando as marcas possíveis, e o outro texto que ainda não está construído, que ainda não é decifrado como algo coerente. O pergaminho permanece, apesar de tudo;

- se esta desconstrução arrasta consigo uma mudança do paradigma (a paisagem tradicional era avaliada como uma situação de equilíbrio, de harmonia e de durabilidade entre as condições do meio físico e a sua 
apropriação por um determinado modo de vida a que estavam associados técnicas específicas, valores, práticas, simbologias, etc.), a violência da mudança pode traduzir-se numa «crise da paisagem», como património ameaçado, como referencial de identidade perdida, ou como empobrecimento cultural. Abstraindo-nos da avaliação estética, a profundidade do trauma pode redundar num processo de negação e de radicalização: a nova paisagem não é reconhecida positivamente; a grelha que a explicava (a construção conceptual da Paisagem) é remetida para uma espécie de arquivo morto da história ou da epistemologia da Geografia. O pergaminho rasgou-se, seguindo-se um período de luto mais ou menos inconformado, do qual apenas se percebe uma longa lamentação...;

- se a mutação da Paisagem é acompanhada pela reconstrução do quadro conceptual que a explicita, se se abdicar dos juízos estéticos anteriores, das atitudes radicais de raiz patrimonialista e identitária, pode vislumbrar-se a re-construção do conceito ao nível estritamente disciplinar (no campo da Geografia ou noutros), correndo-se, no entanto, o risco de entrar em rota de colisão com uma ideia de Geografia e de Paisagem que ainda permanece noutros discursos (meios de comunicação social, literatura, senso comum, etc.). Nesta hipótese a disfunção deixou de estar na paisagem e passou para a relação entre o conhecimento científico e a sua validação social;

- se a reconstrução desse quadro conceptual não abdicar do princípio ecológico (já repescado por Vidal de La Blache da Oekologia de Haeckel (1866) e depois, pela formulação do conceito de ecossistema por Tansley em 1935), então o risco que se corre é o da não clarificação conceptual da Paisagem: como refere Alain Roger, ou se verifica uma «redução» da paisagem aos seus elementos naturais e da sua dinâmica mais ou menos antropizada (o objecto da denominada Ecologia da Paisagem), com o empobrecimento que daí deriva (Roger, 1997: 126-133), ou se assume o verdadeiro conteúdo cultural do conceito e se refunda e clarifica a sua especificidade no campo disciplinar da Geografia.

Sem pretender esgotar as evoluções possíveis, a verdade é que existe uma crescente procura social da paisagem a que a Geografia não dá (ainda) uma resposta satisfatória, apesar de num passado não muito remoto ter sido a disciplina científica que mais aprofundou a questão e que depois a negou radicalmente, com a quimera da suposta cientificidade que o neo-positivismo lhe conferiria e o ónus de exorcisar o descritivismo e o subjectivismo contido no modelo ideográfico da Geografia das Paisagens (Domingues, 1984; HaRVEY, 1979).

Fora do campo disciplinar da Geografia, o uso comum da palavra paisagem tem conotações recorrentes, ora referindo-se a um sentido mais «naturalista» com uma paleta variável de elementos de referenciação ora, mais "culturalista», trabalhado no estilo literário, ou, com ou sem estilo, repescando récitas de um 
mundo rural, bucólico, pitoresco, «autêntico», reflexo da imagem de uma região agrícola ideal (CADIOU; LuginBuHL, 1995). Este sentido do "pitoresco» remonta, em França, aos princípios da protecção da paisagem, e inaugura «uma política da paisagem», já em 1906 (CORBIN, 2001: 164-165).

«No dorso impetuoso do Gerês, dominado por inúmeros picos, o mais alto dos quais é o da Nevosa, crista geodésica da serra com os seus 1545 metros, descobrem-se vales glaciares, desfiladeiros, gargantas, bosques naturais, lagoas paradisíacas, fontes de puríssima água e nascentes de rios. A natureza no seu estado mais puro.» (PÚBLICO, 8/12/2001).

«(...) É porém verdade que sem o Palácio da Pena a serra de Sintra não seria o que é. Apagá-lo da paisagem, eliminá-lo que fosse duma fotografia que registe aquelas alturas, seria alterar profundamente o que já é natureza. O palácio aparece como um afloramento particular da própria massa rochosa que o suporta. E este é decerto o melhor louvor que pode ser feito a um edifício que, nas suas partes, se caracteriza, como já alguém escreveu, por «fantasia, inconsciência, mau gosto, improvisação.» (SARAMAGO, 1998: 186).

«(...) No Verão, os milhos altos sublinham os regatos, parecendo densos canaviais. Em volta dos campos, vicejam as videiras de enforcado, como intermináveis guirlandas verdes. É a quadra em que o Minho bem se poderá dizer uma espécie de Paraíso Verde.» (Guia De Portugal, Vol. IV, Tomo II: 783).

No âmbito disciplinar do Paisagismo, Anne Spirn (SPIRN, 1998), expressa claramente a «linguagem da paisagem», como um desafio para, ao mesmo tempo, ler e reconstruir novos textos paisagísticos nas landscapes e nas cityscapes:

«Grammars of place embody collective wisdom accumulated over generations of life in a particular landscape; their rules are guides it is foolish to ignore. But grammar is a flexible system, not a straitjacket of dictums. It does not dictate how the language of landscape should be used or what meanings ought to be expressed. The methods by which authors combine individual elements to compose landscapes, the rhetoric they employ, and the ideological agendas they promote are the subject of pragmatics, poetics, and polemics of the language of landscape.» (SPIRN,1998: 188).

Esta superação de tipo contextualista, dinâmico, ao contrário das nostalgias quiméricas ou da fuga por uma estética auto-referenciadora (coisa que a land art contemporânea foi capaz de ultrapassar através das linguagens diversas com que interroga os sentidos vários da paisagem), é concordante com a afirmação de Denis Cosgrove (geógrafo, investigador da iconografia e da simbologia das paisagens) quando afirma:

«...simultaneously, the relentless technological and economic compression of space and time, equally characteristic of postmodernity, destroys the local, erasing boundaries, bringing the exotic to our doorstep while rendering the distant familiar and mundane. Nowhere is this more apparent than in the 
global reach of tourism and Net surfing that now frames all the world into fantasy landscapes, imaginatively constructed (...), out of adventitious elements of history, aesthetics, and nature.»(COSGROvE, 1999: 117).

[4] Este curto percurso sobre a paisagem reflecte a dimensão e o conteúdo do problema. Temos, definitivamente, uma relação não resolvida com a paisagem. Enquanto geógrafos, esse conflito latente parece ainda mais agudo e extensível ao próprio conceito de «lugar», tradicionalmente e ainda hoje próximo da conotação que lhe confere Marc Augé (Augé, 1992).

Socialmente, a procura da "paisagem», dos «lugares», do "património» vivido ou percebido, desdobra-se numa heterogeneidade de conteúdos e significações por vezes vagas e contraditórias. Percebe-se, no ruído de fundo, uma vontade de reconstituir uma identidade e um enraizamento local, uma defesa de valores naturais e ecológicos, uma necessidade de qualificar o quadro de vida quotidiano, mas também (e, sobretudo, agora) de chamar a atenção sobre patrimónios e lugares excepcionais.

Parecendo evidente que a paisagem não é uma espécie de «revelação», ou seja, não existe fora da construção individual ou colectiva de um sistema de significantes (organizados de forma "científica» ou outra), torna-se necessário buscar aqui os novos pilares para a re-fundação do conceito. Observando as aproximações mais recorrentes, podemos captar as principais tendências sobre a análise da paisagem:

- No âmbito da nova Ecologia da Paisagem, quer em termos de análise/avaliação, quer em termos de propostas, privilegiam-se os sistemas biofísicos e sua evolução, remetendo para um plano secundário a análise da paisagem como artefacto e construção social (PINO; RodA, 2000). Este tipo de aproximação interliga-se com várias especializações da Geografia Física (a Biogeografia a Geomorfologia, a análise de Riscos Naturais, etc.), enfatizando a defesa dos valores ambientais naturais (ou os resultados perversos da sua degradação ou usos predatórios) e incorporando a evolução do conhecimento de várias Ciências Naturais (Biologia, Botânica, Hidrologia, Climatologia, Pedologia, etc.). De facto, a denominação Ecologia da Paisagem, remonta a 1939 ao biogeógrafo Troll (Landschaf-tokologie). Hoje, este tipo de abordagem, muito ligado a projectos de análise e de intervenção em espaços territoriais alargados, assimilou os princípios do eco-desenvolvimento e do desenvolvimento dito «sustentável», aplicando conceitos como os de biodiversidade, redes e corredores ecológicos, sistemas naturais, unidades de paisagem, etc. Mais do que uma análise morfológica, a Ecologia da Paisagem tem como objectivo a análise funcional dos ecossistemas e a sua (possível) recuperação (conservação da natureza, gestão de espaços em stress), atendendo aos diferentes tipos e graus de bloqueamento, desequilíbrio ou destruição, derivados da ocupação (urbana ou de territórios rurais abandonados ou alterados) do território. A este propósito, Joaquim Sabaté propõe-nos um 
caso interessante, num contexto de urbanização difusa, na Área Metropolitana de Barcelona (SABATÉ, 2000). Para um estudo mais completo da Ecologia da Paisagem, ver, nomeadamente, Burel; BaUdry (1999); FORMAN; GODRON (1986) e FORMAN (1995).

- No âmbito da Estética, da Arquitectura Paisagista, da Etnologia da Paisagem e de outras áreas disciplinares afins, o conceito de Paisagem Cultural assume um papel central como uma espécie de "terceira natureza», conceito que remonta ao séc.XVI: «...la industria de’paesani ha fatto tanto, che la natura incorporata con l'arte à fatta artefice, e connaturale de l'arte, e d'amendue à fatta una terza natura, a cui non saperi dar nome» (Iacopo Bofadio (1541), citado por BRUNON, 1999).

Este «não saber denominar» resta hoje como uma das principais questões acerca de muitas das nossas paisagens, sobretudo aquelas que perderam a sua «funcionalidade» no contexto agrícola tradicional:

«Changer les regards pour transformer les rapports sociaux à l'espace est un processus lent que les professionnels de l'aménagement peuvent accélérer ou infléchir. Mais c'est une évolution d'autant plus importante que le territoire donné à voir forme lui-même les regards de ceux qui l'habitent et le transforment. Plus la maîtrise de cette production simultanée d'espaces de nature extra-urbaine et d'idées de campagne sera voulue par les élus, et plus il sera indispensable de réinventer les récits fondateurs qui l'inspirent...» (DonadieU, 1998: 211).

Pierre Donadieu produz estas afirmações acerca das «campagnes urbaines» dos territórios difusos da cidade emergente, mas a reflexão é extensível a todas os processos de transformação das paisagens agrícolas abandonadas ou em vias de obsolescência (resultando em áreas florestadas, em áreas rurais pressionadas pela segunda habitação, em regiões turísticas, etc.), bem como a projectos de "parcs de campagne».

Sobre estas paisagens "em tensão», produzem-se discursos que reflectem conflitos de representação, de uso, ou de (re)apropriação, designadores, ao mesmo tempo, de uma realidade, da imagem dessa realidade e das referências culturais a partir das quais essa imagem se forma. É esta diversidade de olhares sobre um mesmo espaço, onde se mistura o revivalismo folclórico (uma das piores vias de reconstrução de identidades), e as melhores intenções de reconstrução de um novo sistema de significantes mais de acordo com a condição mutante das paisagens (Voisenat; NotTEGHEM, 1995).

- A Paisagem-Património constitui um caso especial no contexto das Paisagens Culturais. Numa abordagem mais superficial, o valor patrimonial da paisagem reduz-se, muitas vezes, a um exercício de cenografia descolado das condições intrínsecas de produção e de evolução dessas paisagens, e que sobrevaloriza os elementos pitorescos tradicionais (socal- 
cos, muros, arquitecturas vernaculares, ruínas, sítios arqueológicos, lugares excepcionais, simbologias, mitos...), convertidos em ícones de uma «autenticidade cultural perdida» e em imagens de modos de vida supostamente harmoniosos e bucólicos.

A recente classificação do Alto Douro Vinhateiro como Paisagem Cultural Património da Humanidade, permite-nos clarificar melhor os objectivos e as justificações da «patrimonialização» das paisagens.

«The term 'cultural landscape' embraces a diversity of manifestations of the interaction between humankind and its natural environment. Cultural landscapes often reflect specific techniques of sustainable land-use, considering the characteristics and limits of the natural environment they are established in, and a specific spiritual relation to nature. Protection of cultural landscapes can contribute to modern techniques of sustainable land-use and can maintain or enhance natural values in the landscape. The continued existence of traditional forms of land-use supports biological diversity in many regions of the world. The protection of traditional cultural landscapes is therefore helpful in maintaining biological diversity." [UNESCO, Cultural Landscapes (www.UNESCO.org)].

A UNESCO define três critérios de classificação de Paisagens Culturais classificáveis:

- Paisagens intencionalmente criadas pelo homem, por razões estéticas (parques e jardins) normalmente associadas a edifícios ou conjuntos monumentais de carácter religioso ou outro;

- Paisagens que evoluíram organicamente, tendo como origem um imperativo social, económico, administrativo e/ou religioso. Hoje, essas paisagens podem constituir uma relíquia (ou fóssil) do passado, distinguindo-se e conservando-se materialmente através da presença dos seus traços originais; ou podem ainda deter um papel social activo, associado a um modo de vida tradicional em evolução (mantendo, contudo, significativas evidências materiais da sua evolução);

- A terceira categoria corresponde a paisagens cujo interesse se justifica por razões religiosas, artísticas ou culturais importantes, associadas, sobretudo, aos elementos naturais, apesar dos testemunhos culturais poderem ser insignificantes ou mesmo terem desaparecido (cf. www.UNESCO.org).

O Douro Vinhateiro corresponde, claramente à segunda categoria. O desafio é, agora, desenhar e implementar políticas de recuperação, valorização e de protecção que conciliem os valores culturais herdados, e saibam interpretar o sentido das mudanças e a melhoria das condições de vida das populações vistas não como uma espécie de «figurantes de um museu vivo», ou de «jardineiros da paisagem», mas como co-actores principais da construção de um território 
cujo valor identitário também terá que incluir o presente e um projecto de futuro. No entanto, a legitimidade, os critérios, os objectivos, etc., de conservação da paisagem duriense não estarão isentos de conflitos, só ultrapassáveis por um processo alargado de concertação e de mediação de interesses, capaz de ultrapassar um projecto redutor de simples museificação in situ.

\section{(IN)CONCLUSÃO}

A conciliação da Geografia com a Paisagem, implica, por tudo o que foi dito, um exercício de refundação conceptual cujas polaridades tradicionais - natureza e cultura - permanecem. Faltará, porventura, questionar e encontrar novas e velhas interdisciplinaridades que enriqueçam essa construção e permitam superar os obstáculos próprios daqueles que pensam que a Geografia das Paisagens está em crise porque desapareceu aquela espécie de patine ruralista tradicional e atávica que outrora lhe dava sentido. Mudam-se os tempos, mudam-se as sociedades e, com elas, as paisagens. Entre a radicalização ecologista e o discurso negativo sobre as novas paisagens urbanas, haverá com certeza muita matéria para rever e reinventar.

\section{AGRADECIMENTOS}

O autor agradece a amável disponibilidade e as sugestões do Arq. Nuno Portas (FAUP) e da Prof. ${ }^{\text {a }}$ Nicole Vareta (FLUP).

\section{BIBLIOGRAFIA}

AugÉ, M. (1992) - Non-lieux. Introduction à une anthropologie de la surmodernité. Seuil, Paris.

Berque, A. (1995) - Les Raisons du paysage. De la Chine antique aux environnements de synthèse. Hazan, Paris.

BESSE, J.-M. (2000) - Voir la terre, six essais sur le paysage et la géographie. Actes Sud, ENSP/Centre du Paysage, Versailles.

Brunon, H. (1999) - (D)écrire le paysage: un éloge du Lac de Garde au XVI ${ }^{\mathrm{e}}$ siècle. Les Carnets du Paysage, 4, École Nationale Supérieure du Paysage, Versailles: 114-129.

Burel, F.; Baudry, J. (1999) - Écologie du paysage, concepts, méthodes et applications. Éd. Tec et Doc, Paris.

Cadiou; Luginbuhl (1995) - Modèles Paysagiers en Normandie-Maine. In G. Lenclud. Paysage au Pluriel, Collection Ethnologie de la France, Cahier 9, Ed. de la Maison des Sciences de L'Homme, Paris: 18 a 34.

Corbin, A. (2001) - L'homme dans le paysage. Ed. Textuel, Paris. 
Cosgrove, D. (1999) - Liminal Geometry and Elemental Landscape. In J. Corner (ed.). Recovering Landscape-Essays in Contemporary Landscape Architecture, Princeton Architectural Press, New York: 103-120.

Donadieu, P. (1998) - Campagnes Urbaines. École Nationale Supérieur du Paysage, Versailles.

Domingues, A., (1984) - A geografia Regional Vidaliana. Revista da Faculdade de Letras-Geografia, 1. a série, vol. I, Porto: 113-134.

Forman, R. (1995) - Land mosaic. The ecology of landscapes and regions. Cambridge Univ. Press, Cambridge.

Forman, R.; Godron, M. (1986) - Landscape ecology. J. Wiley and Sons, New York.

Guia De Portugal (1986) - Guia de Portugal, Vol. IV, Tomo II. Fundação Calouste Gulbenkian, Lisboa (texto integral da 1. a edição da Biblioteca Nacional de Lisboa em 1924).

Harvey, D. (1979) - Explanation in Geography. Edward Arnold, London.

Lenclud, G. (1995) - Ethnologie et Paysage. In Paysage au Pluriel, Collection Ethnologie de la France, Cahier 9, Ed. de la Maison des Sciences de L'Homme, Paris: 3-19.

Pino, J.; Roda, F. (2000) - Ecologia del Paisatje. In J. SABATÉ, (ed.). El Corredor Sant Llorenç de MuntCollserola, Fundació Politècnica de Catalunya, Barcelona: 36-42.

Roger, A. (1997) - Court traité du paysage. Ed. Gallimard, Paris.

Ribeiro, O. (s/data) - Geografia e Civilização. Livros Horizonte, Lisboa.

RibeIro, O. (1987) - Introdução ao Estudo da Geografia Regional. Ed. Sá da Costa, Lisboa.

Sabaté, J. (ed.) (2000) - El Corredor Sant Llorenç de Munt-Collserola. Fundació Politècnica de Catalunya, Barcelona

Saramago, J. (1998) - Viagem a Portugal. Ed. Caminho, Lisboa.

SpIRn, A. W. (1998) - The Language of Landscape. Yale University Press, New Haven and London.

Voisenat, C.; Notteghem (prefácio) (1995)-Paysage au pluriel: pour une approche ethnologique des paysages. Éd. de la Maison des Sciences de l'Homme, Paris. 